\title{
Integrated Project Teams: The MoD's New Hot Potato?
}

\author{
David M Moore and Peter D Antill
}

\section{$\underline{\text { Introduction }}$}

"We trained hard....but it seemed that every time we were beginning to form up into teams we would be reorganised, [and] I was to learn later in life that we tend to meet any new situation by reorganising: and what a wonderful method it can be for creating the illusion of progress while producing confusion, inefficiency and demoralisation." (1)

"History knows many more armies ruined by want and disorder than by the efforts of their enemies." (2)

With the end of the Cold War and collapse of the Warsaw Pact and Soviet Union, the monolithic threat to Western Europe evaporated and many governments took the opportunity to gather a 'peace dividend' from the new situaton. This has meant the reduction of defence budgets and the reallocation of those funds to other areas of public spending. However, the 'New World Order' has taken a direction which is rather different from that forecast. Instead of the one major threat, there is now a multitude of smaller ones, which cannot be met with large conventional forces stationed on the Central Front, but will have to be countered by smaller intervention forces capable of rapid projection.

This reorientation, so far as the UK Armed Forces was concerned, was announced in the Strategic Defence Review (SDR), in July 1998. It also recognised the need to do more with a smaller budget, given the rate of defence inflation (which is generally above normal economic inflation). Faced with criticism stretching back many years which accused the MoD of having an over bureaucratic approach to procurement (3), failing to prevent high defence inflation and in-service date slippage, the Smart Procurement Initiative (SPI) was announced as part of SDR. It is hoped that these "radical changes ... will deliver a forward looking organisation using up to date acquisition processes and procedures. The emphasis will be on flexibility ... and continuous evaluation to avoid any danger of stagnation." (4) 'Faster, better, cheaper' (5) has become the new catch phrase for the supporters of change but for others, the change in mindset is almost too big to be practical. For them, SMART could be said to stand for Same Methods Appearing Rather Trendy.

SPI involves a change from the previous Downey procurement cycle and a move to a more streamlined Acquisition cycle. The structure of this cycle aims to reduce risk by carrying out a more comprehensive assessment of projects at an earlier stage, while streamlining the approval process. (6) Formal approval has been reduced from three to two occasions, the first time is during the concept phase (Initial Gate) and between the assessment and demonstration phases (Main Gate).

Central to the implementation of SPI is the introduction of Integrated Project Teams (IPTs) which are part of the drive to move from a functionally based management and reporting structure to a project based organisation. They will drive the management of 
major defence equipment procurement, balance the trade-offs between performance, cost and time, within boundaries set by the approving authority. IPTs will bring together all defence stakeholders and industry under a single team leader. They will be responsible for the complete lifecycle of the piece of equipment, and once in service, will move from what was the Procurement Executive (PE), now the Defence Procurement Agency (DPA), to the Defence Logistics Organisation (DLO) where they will manage equipment support.

Since the announcement of Smart Procurement much has been written on the potential benefits that IPTs will hopefully bring. It is supposed that they will improve the interface with industry, create a better understanding of requirements and establish an environment where industry is motivated to perform (7) and so reduce cost, risk and time into service while improving product quality. The formation of a team should provide continuity, consistency, flexibility and increased performance due to the integration of a wide-range of functional activities and decision-making, as well as increased motivation. These may well be gallant objectives, but how achievable are they? What obstacles does the MoD face in the implementation of the IPTs? Have they grasped a 'hot potato'?

\section{$\underline{\text { A Not-So-New, New Idea }}$}

IPTs have been described as the "centrepiece of Smart Procurement" (8) which itself has been described as a "revolution and complete cultural change in MoD procurement". (9) Many of the initiatives in Smart Procurement may well be revolutionary, but IPTs themselves are not a new idea. The US DoD adopted the concept in 1995 and introduced IPTs, (Integrated Product Teams) which consisted of "everyone with a stake in the outcome or product of the team, including the customer and suppliers". (10) Also, the Society of British Aerospace Companies (SBAC) states that IPTs have been an integral part of the aerospace industry for the past five years. They refer to them as "cells of individuals, whose skills span the design, development, manufacture and through-life aspects of a platform or weapon system" and maintain that IPTs are a key element wherever lean manufacturing is practised. (11)

Similar thinking was expressed in the 1983 'Value for Money' paper, where the Government recognised the need for improved management practices and "sharing the risks and costs, through international collaboration and/or joint ventures with industry." (12) These ideas have been known variously as Integrated Procurement Management Teams, matrix resourcing or Multi Disciplinary Groups. (13) However, they were organised along functional lines, and according to McKinsey, characterised by an arms length relationship between the MoD and contractors. This in turn inhibited the full exchange of information thereby preventing effective problem solving. (14) IPTs could be viewed as another name in what is currently good management practice. The Challenger 2 project team for example, maintains an almost daily contact with their opposite numbers in industry at Project Manager level. (15) In terms of in-service support there are cases where MoD and industry teams are closely integrated, one example being the joint $\mathrm{RN}$ and contractor project teams established at Devonport Dockyard to manage surface ship and submarine refits.

\section{Industry: Competition, Participation and Partnership}


Even after Smart Procurement, competition remains the MoD's primary tool for achieving value for money in defence contracts. Industry participation in the IPTs will vary according to where in the decision cycle the project is and according to the competitive situation of each phase. (16) Industry may be involved in one of two ways. Firstly, through the participation of selected individuals from potential prime or sub contractors and secondly through secondment of an individual who is not from a potential supplier to the project. In the second case, it would be possible for that individual to be appointed team leader. (17) The introduction of IPTs will make it harder to strike a balance between industry participation and competition, and this may well be difficult to achieve in practice, despite what the Smart Procurement documentation says.

IPTs will form during the concept phase where it is quite likely that industry will be 'co-opted' on to a team, rather than being a full member. This is because several companies would be involved in providing solutions as part of the User Requirement Document (URD) process. (18) It is here that the first problem of competition is apparent. In order to produce an effective URD, the MoD requires industry to comment on aspects such as target costs, time scales and performance. Contractors will be loathe to pass on information that they feel will give a rival an advantage downstream. This will be even more apparent if more than one company has been 'co-opted' into the project prior to the announcement of a prime contractor. At the same time, Smart Procurement expects industry to be more willing to release data, than they have in the past. (19) Apart from stating that IPT leaders will have to make arrangements to ensure that commercially sensitive information is protected from competitors, there is little advice on how this might be undertaken.

Once the competition has been launched by Invitation to Tender (ITT), the companies' 'co-opted' membership of the IPT will be temporarily suspended. Contributions made by contractors during the previous phase would however, be taken into account during the selection process. There is a fear that this process will not generate fair competition. The MoD could be accused at first glance of using the 'carrot' of favouritism during selection as an incentive to contractors to share information during the URD phase. Furthermore, how can this be fair to a contractor who joins at the ITT phase without having been a 'co-opted' member?

Smart Procurement will see the introduction of a segmented approach to acquisition. There will be three tiers: low risk and unit cost items, minor projects of intermediate scale and technical risk, and major projects characterised by substantial risk and high unit cost. (20) It is the latter tier that has received most of the attention so far, and provided a number of the IPT pilot projects announced under Smart Procurement. IPTs will be formed for Tier 2 projects as well, but will be capability based, and responsible for more than one project. As an example, the Land Systems section of the DPA established a Dismounted Close Combat (DCC) IPT responsible for fiftytwo projects. (21) In this sort of situation, it will be difficult to manage contractor participation whilst guaranteeing no party gains a competitive advantage. This view has been taken by the DPA who suggest that multiple equipment IPTs will work for Commercial off the Shelf (COTS) procurement but not developmental ones where developers are reluctant to pass on technological information. (22) 
Additionally, while there is no intention in SDR to return to the cosy world of cost plus arrangements, post main production contract partnering seeks an environment where participants recognise common goals and work towards them creating a 'winwin' situation. This approach could invite accusations of mediocrity. The DPA IPT members will be conscious of their responsibility for prudent management of the public purse, while industry members will feel a responsibility towards their shareholders. There is a danger that a "company knowing that it has an established close relationship with government may lose some of the leanness it has developed in the search for value for money". (23) While there may well be a middle ground, human nature doesn't always naturally seek it, and when the necessity to cut costs is removed, inefficiencies may develop. In order to avoid this, both sides must remain convinced as to the benefits of partnership, and contracts must be structured so as to allow industry to benefit from efficiencies achieved. In the longer term, partnering post contract must support the ongoing viability of both IPTs and industry. The IPTs need to support the equipment through its life, at acceptable cost, and industry must remain profitable to survive.

This is an area that must have further work. Industry must remain motivated so that it will enter a dialogue with the MoD during the early stages of a project so that it can gauge requirements quickly and accurately. If this is not achieved, it is unlikely that equipment will be delivered on time, to specification or budget, and it will appear that the new procurement system is no better than the last.

\section{Organisational Issues}

There are a number of organisational issues that need to be addressed with regard to IPTs. One of the major criticisms of previous efforts was the discontinuity and confusion arising out of the regular turnover of staff and rotation of roles. (24) If the MoD is not careful, IPTs may repeat this mistake. Whilst Smart Procurement rightly acknowledges the need for the team leader to stay in post for four to five years, little attention is paid for the necessity for there to be continuity in the rest of the team as well. McKinsey actually highlighted the need for the Operational Requirement (OR) or Capability Managers to stay in post for even longer (25), but no reference can be found as to the need to adjust military or civil service tour lengths.

The subject of the MoD 'ownership' of IPTs is rife with confusion. The main purpose of an IPT is to manage the whole lifecycle of a product that will move from CDP to Chief of Defence Logistics (CDL) once the equipment is in service. The detail of the transfer process is yet to be resolved. Consequently, there is talk of running parallel project teams within DLO. (26) This is obviously contrary to the 'lean' intent of Smart Procurement. Additionally, it is unclear where the new IPTs will sit in the new MoD hierarchy. Smart Procurement sees the eventual creation of a central defence customer, the Capability Manager (CM) whose relationship with IPTs is seen as "critical to achieving the full potential of Smart Procurement." (27) However, at this stage, it is unclear as to who will own IPTs in the future.

Integration of internal stakeholders is essential to the IPTs success. Early signs have been that this may not always be possible. OR branch is not capable of meeting its membership commitments, of the twenty-five IPTs within the DPA Land Systems section, at the last count, only seven had OR representation. (28) To enhance 
stakeholder integration IPT leaders are empowered to consider co-locating core members. (29) This however will be difficult as the three major internal stakeholders (Capability Manager, DPA and DLO) occupy three sites separated by between fifty and 120 miles.

\section{$\underline{\text { Culture and Training - Converting the Dinosaur }}$}

The creation of IPTs will mean a coming together of people from different organisational and business cultures. IPTs will have to overcome differences in public and private sector organisations where "the former has a need to spend money legally, whereas in commerce it must be spent efficiently." (30) A too closer relationship could see profit orientated companies exploiting the government by charging as much as possible. Industry tends to be less averse to risk than the MoD and perceives that responsibility and authority are usually devolved to lower levels as well. Culture differences can be illustrated by the fact that some industrialists are yet to be convinced of the merits of Smart Procurement in that the chairman of the SBAC commented that "our main worry is that Smart Procurement is full of good ideas, but will they ever be exercised?" (31) Industry and the MoD operate different reward philosophies, which will be a barrier to cohesion. A good year for a civil servant or military officer means a favourable personnel report, for an industrial executive it is a hefty payoff in a profit related pay scheme. (32) These differences will have to be carefully managed if team cohesion is not to suffer.

IPTs will represent a shift from current procedures and it is inevitable that there will be some resistance to that change. According to the US Loral Federal Systems (who published ten lessons learned from operating Integrated Product Teams) resistance to implementation is a major obstacle to success. In their opinion, overcoming the resistance means people must "understand the concepts, see the benefit to the project and understand the changes to their role." (33) Strong leadership and change management are essential for IPTs to succeed.

It has been written that "no great improvements in the lot of mankind are possible until great change takes place in the fundamental constitution of their modes of thought." (34) The 1990s have seen substantial upheavals in the defence arena, and although Smart Procurement is not necessarily radical, it is being imposed on a traditionally conservative body. Commercially, value for money through the medium of competition has been the main driver for the PE since the 1970s. Those involved have seen themselves in personal competition with both other MoD employees and industry. This adversarial relationship was accentuated by the lack of accountability and delegated authority. (35) In short, for most PE employees, there has been little incentive to achieve a closer relationship with OR, the Defence Evaluation and Research Agency (DERA), or industry. Taken from an outside viewpoint, the rationale for reform is undeniable, but it is the people from each constituent body that will make the IPTs work, and thus it is those people who must be convinced of the real benefit of change.

The answer is not an obvious one though, and a workforce does not tend to accept change lightly. Many civil servants who have been in their job a long time, are being asked to give up security for flexible employment, potential location changes and a more complex working environment. IPTs are about co-ordination and empowerment, 
which could however be used as a reward. Potentially, those reluctant to change may be sidelined whilst the proactive are pushed forward to develop their careers. Fundamental to this process of change are education, leadership, the commitment of senior management, and a thoughtful personnel policy.

In this vein, it is encouraging to note the recognition that the skills needed in procurement can no longer be acquired by either osmosis or experience. The IPT Pilot Guide $4^{\text {th }}$ edition and supporting information (36) outlines a series of core capabilities that are expected of IPT leaders and their teams, and a comprehensive training programme in both technical and teaming / communication skills is intended. Additionally, innovative proposals for the establishment of Commercial External and MoD Internal consultants will do much to set a solid foundation for an effective management structure.

To work effectively, the DPA must attract and promote the highest quality personnel. Up until now, while a few civil servants have made a career from procurement, most senior managers have moved between the PE, MoD HQ and possibly DERA. For the military, procurement specialisation is a rarity (compared with logistics). The introduction of an acquisition stream (37) for both military and civilian personnel will bring a previously unseen professionalism to the process. Unfortunately, for the military, it is probable that acquisition will remain a second choice career path. What is true for the government is also true for industry. In the case of secondment to IPTs, industry will probably provide their best people when they see it as in their best interest to do so. As regards the competition to lead teams, the situation is more complex. Recruitment form the commercial sector will be dependent not only on job satisfaction and long term benefit, but also on financial reward and flexible contracting not normally present for public employees. The IPT Pilot Guide provides the capability to pay bonuses for exceptional performances but pitching them at a suitable level and paying realistic base salaries will be difficult issues.

\section{$\underline{\text { Some Further Obstacles }}$}

'Faster, cheaper and better' has become the slogan for Smart Procurement, and for IPTs to succeed they must achieve this objective as a minimum. It is important to note that the MoD does not itself see the IPTs as a guarantee of success. They state that "success will depend on the calibre of the team leader and their authority, both within the team and the quality of relations with industry and the customer". (38) In such an environment of uncertainty, how can IPTs be expected to achieve the aim of Smart Procurement?

It can be argued that the ability of IPTs to reduce costs in the short term is limited because so many projects are already advanced and set in their ways. (39) Around twenty-five per cent of the projects covered by the 1997 NAO Major Projects Report accounted for some fifty per cent of the annual procurement budget. The integration of current projects is an area that must be addressed. (40) A poor performance from an existing non-IPT project that attracts criticism from the NAO has the potential to undo all the good work of the IPT pilot programmes.

Critics of Smart Procurement argue that the success of IPTs will be hindered by the lack of investment. These reforms have emerged in an era where the defence budget 
remains flat and unit costs of defence equipment maintain a rise of around 10 per cent a year. (41) To this must be added the probability that IPTs will require a greater investment and rigour at the front end of the acquisition process in order to ensure capability specifications are met. (42)

\section{$\underline{\text { Conclusions }}$}

To conclude, following years of criticism, the MoD is attempting to modernise and update its procurement system. Central to these measures is the introduction of Integrated Project Teams that bring together all the stakeholders. In the course of this, much has been said about the potential benefits of IPTs but little about their limitations.

So, what factors does the MoD have to consider, if they are not to get their fingers burnt by the new 'hot potato' that are IPTs?

- Stakeholder Co-location - If one accepts that stakeholders should be housed together if IPTs are to stand the best chance of success (43), then it follows that IPT leaders must have the ability to co-locate stakeholders. At the moment the main internal stakeholders are geographically separated and in the case of OR cannot fulfil all their IPT commitments. There is an urgent need for internal stakeholders to be brought together on one site. While some elements of OR may join the DPA at Abbeywood, to improve the chances of the IPTs succeeding and give industry a single point of contact throughout the whole lifecycle of the project, CDL must join. If the site at Abbeywood is unsuitable then an alternative site should be found. Eventually, both CDL and CDP could merge (along with their respective organisations) to create a Chief of Defence Support (Materiel) or similar.

- Information Technology - If it is not possible to overcome geographic separation, IT and EDI must be exploited to the full to bring stakeholders together within a common electronic network. All parties, including industry, must have the ability to exchange information over an Internet, which must also have the ability to hold online conferences.

- Training and education - This is essential for all stakeholders so that cultural barriers can be broken down. The Smart Procurement documentation discussed the introduction of an Acquisition Stream with "career paths and an endurable culture of change". (44) For this to work, continuity must be provided to all posts, not just the team leader's, and the team leader must be able to adjust tour lengths at their discretion. Personnel must be thoroughly trained in IPT practices. Smart Procurement proposes personnel attend modules at the time of appointment and at various stages of a project according to individual need. (45) An IPT training strategy is required urgently.

- Rewards - To offset the differences in MoD and military remuneration, there is a need to introduce some form of reward scheme for civil servants and military officers. At the same time, incentives should be introduced to reward successful IPT performance. Suggestions proposed under Smart Procurement include performance-related bonuses and 'shares' in an IPT terminal bonus. 
- Industry Support - In order to ensure IPT success, industry must be motivated to co-operate fully in the IPT process. Without their full support, IPTs will fail to improve the current procurement system. It is possible that this could be achieved through a combination of financial and non-financial methods. The former would include milestone payments and the offer of a completion bonus if the project was completed on or ahead of schedule, to budget and specification. Non-financial methods would be aimed at breaking down some of the cultural barriers and would include the involvement of industry in IPT training and education. The US DoD has found that IPTs work better when contractors have an established IPT system. (46) The existence of an IPT culture within a contractor should be included as a selection criterion.

- Independent Regulator - The appointment of an independent regulator would protect the MoD from the risk of exploitation by single source suppliers. This idea has already been mooted, and the regulator would have the same role as Oftel in regards public telecommunications and BT. (47) A supervisory role during the concept phase of the Acquisition Cycle should be added as well as this would protect the MoD from accusations of unfair competition when more than one company is 'co-opted' into an IPT. It may also give potential customers the confidence to share information, without fear of rivals gaining an advantage.

\section{$\underline{\text { References }}$}

1. Petronius, Arbiter, Greek Navy, 210 BC.

2. Richelieu in Van Creveld, Martin. Supplying War, Cambridge University Press, 1995, p. 17.

3. See for example Kincaid, Bill. 'SMART Procurement: Revolution or Retrogression?', Conference on Managing the Revolution in Military Affairs, RMCS Shrivenham, 11 November 1998 and A Dinosaur in Whitehall. Brassey's, 1997.

4. Ministry of Defence. Strategic Defence Review, Cm3999, 10 July 1998, Supporting Essay 10, paragraph 6.

5. Ministry of Defence. Strategic Defence Review, Cm3999, 10 July 1998, Chapter 8, paragraph 161 .

6. Jdir, C A. 'Strategically Smart: UK's ticket to future cuts', Jane's Defence Industry Report, 1 July 1998, p. 7.

7. See DPA Web Site, 'Take your Partners: Partnering arrangements between MoD and its Suppliers', http://www.mod.uk/dpa/news/aw0199.htm. Galloway, Iain. 'Private finance comes of age', Defence Procurement Analysis, Autumn 1998, pp. 17 - 19. Financial Times Survey, 'Private Finance Initiative', December 11 1998.

8. Nolan A. 'MoD dream teams on trial in flagship projects', Supply Management, Volume 3, Issue 22, 5 November 1998, p. 14.

9. Cook, N. 'Smart Moves', Jane's Defence Weekly, 9 September 1998. Comment attributable to the Chief of Defence Procurement, Sir Robert Walmsley.

10. US DoD, Office of the Under Secretary of Defense. Integrated Product and Process Development, 5 February 1996, p. 2. 
11. Op Cit. Cook, N.

12. Pattie, G. Minister of State for Defence Procurement. "Value for Money in Defence Equipment Procurement', Defence Open Government Document, October 1983, Section II, p. 5.

13. Ministry of Defence. 'Smart Procurement: The Integrated Project Team', http://www.mod.uk/policy/smart/ipt.htm, p. 2.

14. McKinsey and Company. Transforming the UK's Defence Procurement System. Final Report, 20 February 1998, p. 1.

15. Inglis, B. 'Challenger 2 Project', Presentation to 13 MDA, MoD(PE) Abbeywood, 8 March 1999.

16. Ministry of Defence. 'Smart Procurement: The Role of Industry', http://www.mod.uk/policy/smart/industry.htm, p. 2.

17. Ibid. p. 3.

18. Ibid. p. 4.

19. Ibid.

20. Ministry of Defence. Strategic Defence Review, Cm3999, 10 July 1998, Supporting Essay 10, paragraph 11.

21. Brown, D. 'Dismounted Close Combat IPT', Presentation to 13 MDA, MoD(PE) Abbeywood, 8 March 1999.

22. Hudson, D. 'Introduction to $\mathrm{MoD}(\mathrm{PE}) / \mathrm{DPA}$ and Smart Procurement', Presentation to 13 MDA, MoD(PE) Abbeywood, 8 March 1999.

23. Taylor, Professor T. 'Smart Procurement and the Partnership with Industry', RUSI Journal, April 1998, pp. 41 - 46.

24. Op Cit. McKinsey and Company, p. 11.

25. Ibid.

26. Op Cit. Hudson.

27. Ministry of Defence. 'Smart Procurement: The Customer Supplier Relationship', http://www.mod.uk/policy/smart/customer.htm, p. 1.

28. Op Cit. Hudson.

29. Op Cit. Smart Procurement: The Integrated Project Team, p. 3.

30. Op Cit. Taylor, Prof. T. p. 41.

31. Op Cit. Cook, N.

32. Ibid.

33. Popick, P R and Shead, S A. 'Ten Lessons Learned from Implementing Integrated Product Teams', http://www.stsc.hill.af.mil/CrossTalk/1996/Jultenlesso.htm.

34. Mill, J S. Autobiography. 1873, Chapter 7.

35. Kincaid, Bill. 'Smart Procurement for Jurassic Park', RUSI Journal, December 1997, pp. $14-17$.

36. IPT Pilot Guide Edition 4, 19 January 1999 - Personnel and Training Model and Smart Procurement Implementation Team Information Pack for Integrated Project Team Leader Candidates, February 1998.

37. Ministry of Defence. Strategic Defence Review, Cm3999, 10 July 1998, Supporting Essay 10, paragraph 25.

38. Op Cit. Smart Procurement: The Integrated Project Team, p. 1.

39. Op Cit. Taylor, Prof. T. p. 41.

40. Ibid. p. 46.

41. Ibid. p. 41.

42. Smith, K. 'What should Smart Procurement be?', RUSI Journal, April 1998, pp. $37-40$. 
43. Fleming, Q W. 'Integrated Project Development Teams: Another Fad ... or a Permanent Change?', Project Management Journal, Volume 28, Number 1, 1997, pp. $4-11$.

44. Ministry of Defence. 'Smart Procurement, Personnel and Training', http://www.mod.uk/policy/smart/personnel.htm, p. 1.

45. Ibid. pp. $2-3$.

46. Op Cit. US DoD, p. 11.

47. Op Cit. Taylor, Prof. T. p. 42. 